\title{
What Is the Evidence to Support the Use of Therapeutic Gardens for the Elderly?
}

\author{
Mark B. Detweiler ${ }^{1}$, Taral Sharma ${ }^{2}$, Jonna G. Detweiler ${ }^{3}$, Pamela F. Murphy ${ }^{4}$, Sandra Lane ${ }^{5}$, \\ Jack Carman ${ }^{6}$, Amara S. Chudhary ${ }^{2}$, Mary H. Halling ${ }^{3}$ and Kye Y. Kim ${ }^{7} \bowtie$ \\ ${ }^{1}$ Psychiatry Service, Veterans Affairs Medical Center, Geriatric Research Group, Salem, VA, Virginia Tech-Carilion School of Medicine, \\ Department of Psychiatry and Behavioral Medicine, Roanoke, VA, USA \\ ${ }^{2}$ Virginia Tech-Carilion School of Medicine, Psychiatry Residency Program, Roanoke, VA, USA \\ ${ }^{3}$ Geriatric Research Group, Veterans Affairs Medical Center, Salem, VA, USA \\ ${ }^{4}$ Geriatric Research Group, Veterans Affairs Medical Center, Salem, Virginia, Adjunct Faculty, Virginia Tech, Blacksburg, VA, USA \\ ${ }^{5}$ Horticulture Program Director, Geriatric Research Group, Veterans Affairs Medical Center, Salem, VA, USA \\ ${ }^{6}$ Design for Generations, LLC, Medford, NJ, USA \\ ${ }^{7}$ Carilion Center for Healthy Aging, Virginia Tech-Carilion School of Medicine, Department of Psychiatry and Behavioral Medicine, Roanoke, VA, USA
}

Horticulture therapy employs plants and gardening activities in therapeutic and rehabilitation activities and could be utilized to improve the quality of life of the worldwide aging population, possibly reducing costs for long-term, assisted living and dementia unit residents. Preliminary studies have reported the benefits of horticultural therapy and garden settings in reduction of pain, improvement in attention, lessening of stress, modulation of agitation, lowering of as needed medications, antipsychotics and reduction of falls. This is especially relevant for both the United States and the Republic of Korea since aging is occurring at an unprecedented rate, with Korea experiencing some of the world's greatest increases in elderly populations. In support of the role of nature as a therapeutic modality in geriatrics, most of the existing studies of garden settings have utilized views of nature or indoor plants with sparse studies employing therapeutic gardens and rehabilitation greenhouses. With few controlled clinical trials demonstrating the positive or negative effects of the use of garden settings for the rehabilitation of the aging populations, a more vigorous quantitative analysis of the benefits is long overdue. This literature review presents the data supporting future studies of the effects of natural settings for the long term care and rehabilitation of the elderly having the medical and mental health problems frequently occurring with aging.

Key Words Therapeutic garden, Rehabilitation, Elderly.

\section{INTRODUCTION}

It is well known that the population around the world is aging at an unprecedented rate and is an enduring global phenomenon, with profound implications for many facets of human life. A 2010 report from the Population Division, Department of Economic and Social Affairs of the United Nations predicts that the United States will experience major

Received: June 18, 2011 Revised: October 11, 2011

Accepted: December 22, 2011 Available online: May 22, 2012

$\triangle$ Correspondence: Kye Y. Kim, MD

Carilion Center for Healthy Aging, Virginia Tech-Carilion School of Medicine, Department of Psychiatry and Behavioral Medicine, 2001 Crystal Spring Avenue, Suite 302, Roanoke, VA 24014, USA

Tel: +1-540-981-7653, Fax: +1-540-981-7469

E-mail: kykim@carilionclinic.org

(a) This is an Open Access article distributed under the terms of the Creative Commons Attribution Non-Commercial License (http://creativecommons.org/licenses/bync/3.0) which permits unrestricted non-commercial use, distribution, and reproduction in any medium, provided the original work is properly cited. increases of individuals 65 years old and older, from $13.3 \%$ at this time to a projected $20.1 \%$ in 20 years. ${ }^{1}$ However, the Republic of Korea will surpass the American aging with one of the greatest increases in elderly populations in the world, from $11.5 \%$ in 2011 to almost one quarter (24\%) of the population in 2031. The United Nations also predicts that in 20 years a larger proportion of the Korean elderly (22.4\%) will be very old, 80 years old or older. Clearly these nations need to prepare for the dramatic changes in population demographics.

For some elderly, aging brings declines in cognition and function that may precipitate losing independent living. ${ }^{2}$ In general, for those persons with advancing medical and psychiatric problems, declining cognitive and functional changes may necessitate entering assisted living or dementia residences. ${ }^{3}$ In either case, the role of health scientists is to find the most supportive and pleasant environments during these latter chapters of life. Economics will also play a major role in 
determining some of the most cost-effective ways to humanely care for the elderly, as the proportions of working individuals will greatly diminish in the future.

Constructing rehabilitation centers, assisted living or dementia residence gardens that encourage autonomy and sensory stimulation is an economically sound, non-pharmacological strategy for improving the quality of life for persons needing these types of residences. ${ }^{4.7}$ Therapeutic gardens offer elderly residents the choice of leaving the residential unit for a natural setting designed to promote exercise and stimulate all the senses. Another aim of therapeutic gardens is to promote ambulation, positive reminiscences, decreased stress and stabilized sleep wake cycles. ${ }^{8,9}$ As described in this article, exposure to nature has been associated with reduction in pain, improvement in attention and modulation of stress responses. In addition, some studies have reported that having free access to an outdoor area may reduce some agitated behaviors, medications and falls in dementia residents.

Horticulture has been used as a therapeutic modality since ancient times. However, despite its long use in fields of physical therapy, psychiatric occupational and recreational rehabilitation, there are few strong quantitative studies supporting the efficacy of garden settings for therapy and rehabilitation. ${ }^{10}$ Nevertheless, there is an increasing body of literature supporting the theoretical therapeutic mechanism of nature on attention, stress and healing. We present some of the findings in the English literature that support initiating research in the effectiveness of horticultural therapy in garden settings for elderly individuals.

\section{HISTORY OF HORTICULTURE AS A THERAPEUTIC MODALITY}

Horticultural therapy is a relatively new discipline combining horticulture and rehabilitation disciplines. It employs plants and gardening activities in therapeutic and rehabilitation activities to improve human well being. ${ }^{11}$ Historically, the use of horticulture to calm the senses dates as far back as 2000 BC in Mesopotamia. Around 500 BC, the Persians began creating gardens to please all of the senses by combining beauty, fragrance, music (flowing water) and cooling temperatures.

In the USA, the therapeutic benefits of peaceful garden environments have been understood since at least the 19th century. Dr. Benjamin Rush, considered to be the "Father of American Psychiatry" in the United States, reported that garden settings held curative benefits for people with mental illness. ${ }^{11}$ A professor of the Institute of Medicine and Clinical Practice at the University of Pennsylvania known for his role in the development of modern psychiatry, Dr. Rush published his book Medical Inquiries and Observations Upon Diseases of the Mind in 1812. In it he stated that "digging in a garden" was one of the activities that distinguished those male patients who recovered from their mania from those that did not engage in garden activities. ${ }^{12}$ Based on these observations, the hospital grounds included landscape-shaded paths through grassy meadows. Gradually in the United States, agricultural and gardening activities were included in both public and private psychiatric hospitals.

The use of horticulture to improve the care of veterans took a large step forward during WWI. The enormous number of returning wounded veterans to US hospitals precipitated the start of horticulture use in the clinical settings. Initially, horticulture was used for occupational and recreational therapy as part of psychiatric rehabilitation. The Rusk Institute of Rehabilitative Medicine, associated with New York University Medical Center, was the first US medical center to add a greenhouse to its rehabilitation unit in 1959 for interdisciplinary diagnostic and rehabilitative therapy. ${ }^{13}$ In 1972 the Menninger Foundation teamed with the Horticulture Department at Kansas State University to provide training for undergraduate students in the mental health field. This would lead to the first horticultural therapy curriculum in the US.

\section{CURRENT SCIENTIFIC UNDERSTAND- INGS OF THE EFFECTIVENESS OF HORTICULTURAL THERAPY FOR THE ELDERLY}

Horticultural therapy (HT) and exposure to gardens has been shown to have positive benefits for the elderly. Indoor gardening has been reported to be effective for improving sleep, agitation, and cognition in dementia patients. As a cognitive therapy, HT helps clients learn new skills and regain lost skills. It is a restorative technique to improve memory, attention, sense of responsibility and social interaction with few to no adverse side effects. Moreover, HT has been found to reduce stress, ${ }^{14-17}$ to increase feelings of calm and relaxation, ${ }^{18,19}$ to foster a sense of accomplishment ${ }^{20,21}$ and to improve selfesteem. ${ }^{18,22-25}$ As a result of activities in a green setting, there was a significant improvement in self-esteem in nine out of ten case studies. ${ }^{26}$ Randomized controlled studies of larger sample size are needed to confirm treatment effect. ${ }^{27}$

While the literature supports the role of horticultural therapy in improving attention ${ }^{28,29}$ and reducing stress, ${ }^{30-32}$ this knowledge has not resulted in many quantitative studies about chronic pain, cardiac and post stroke rehabilitation. A few descriptive case studies, often without control patients, to delineate the benefits of the restorative natural setting over traditional rehabilitation settings, have been published about rehabilitation patients in garden settings: cardiac; ${ }^{33} \mathrm{ampu}-$ 
tee; $;^{34,35}$ post stroke ${ }^{7,36-38}$ and chronic pain. ${ }^{39}$

\section{The therapeutic garden}

Since Homo sapiens evolved in a natural environment, an intrinsic physiologic and psychological positive reaction to nature has developed that is involved in maintaining the human being's homeostasis. Thus, an automatic and subconscious propensity to react to nature in a positive manner is theorized. ${ }^{40}$ Orians ${ }^{41}$ proposed that there is higher attentional response to environmental cues such as trees and natural features associated with landscapes providing sources of food and water.

Most importantly, therapeutic gardens should contain familiar elements that are typical of the region and activities that elders may have participated in at previous stages of their lifetime.

Therapeutic garden design focuses on increasing sensory stimulation by providing assisted living or dementia residents access to the outdoor spaces on a daily basis. Dementia facilities have elaborate structural and electronic devices to prevent residents from eloping and to reduce the risk of injury or death. ${ }^{42}$ Therapeutic gardens provide assisted living or dementia residents a safe environment for exercise, reflection and passing time with other residents, friends or family members. They may also have structured spaces that reduce disorientation.

To stimulate the senses, therapeutic gardens typically include a variety of plants to promote visual, olfactory, and tactile stimulation and to attract birds and butterflies. Also, trees may provide shade, color, seasonal variation, and sound when the leaves rustle in the wind. Walking paths promote movement, encourage contact with plants (all nontoxic and noninjurious), and lead the residents to protected areas for sitting and socializing. ${ }^{43}$ For the dementia populations, the paths should be continuous with no dead ends to encourage cardiovascular exercise. Vegetables and herbs can be planted to expand visual and tactile experiences and help with improved eating. Some therapeutic gardens include raised planters where the residents can use their hands or simple safe tools for digging and other activities with supervision. Gardens should be designed to stimulate the senses and to encourage older adults to spend time outside in nature. Horticultural therapy may also be used to promote gardening interests both as pastimes and to stimulate function and cognition. ${ }^{44}$ For climates with extended periods of inclement weather, therapeutic gardens may have enclosed perimeter walkways with exits into the garden. Large windows looking out into the garden allow the residents full view of the garden in order to promote positive ideations and to remind them of the presence of the garden. ${ }^{45}$

\section{Reduction of pain}

Therapeutic gardens in residences for the elderly may reduce pain perception. The sensory stimulation of a natural setting has been proposed to reduce the consciousness of unpleasant internal and external stimuli. In a randomized controlled study utilizing murals of nature sights and tapes of nature sounds supplied to patients undergoing bronchoscopy, pain, but not anxiety, was significantly reduced. ${ }^{46}$ It was suggested that such non-intrusive interventions may reduce the need for pharmacologic analgesia while the patient is undergoing painful, invasive procedures. The mechanism of this distraction therapy was not identified.

With aging, the risk of needing rehabilitation for acute and chronic medical problems such as cognitive decline, altered mental status, strokes, heart attacks, and surgical procedures increases. Preliminary studies suggest post trauma and post surgical patients have improved treatment outcomes secondary to greater exposure to natural settings. Ulrich ${ }^{47}$ performed one of the classic studies on the positive effect of passive interaction with garden settings to reduce pain. Post-cholecystectomy patients having a window with a view of nature required fewer high potency analgesics and had shorter hospital stays than patients with windows having a view of a brick wall.

Another measure of the strength of a passive interaction with nature involved the role of sunlight in post cervical and lumbar surgery patients. Walch et al. ${ }^{48}$ found that patients in high sunlight rooms had less perceived stress, utilized fewer analgesic medications and had lower costs for pain medications. Also, there was a trend, although it was not statistically significant $(\mathrm{p}=0.58)$, toward reduced perception of pain. In a third passive interaction study, Park $^{49}$ reported that having plants in the hospital room following thyroidectomy, appendectomy and hemorrhoidectomy shortened patients' post operative hospitalization, reduced analgesic use, and reduced pain, anxiety and fatigue when compared to the control group that had no plants in their rooms.

\section{Improvement in attention}

Many patients in horticulture or rehabilitation therapy have attention deficits due to either internal or external negative stimuli secondary to clinical entities such as pain, post-stroke sequelae, head trauma, anxiety, depression or dementia. James ${ }^{50}$ hypothesized that navigation of one's complex external environment is facilitated by two components of attention, voluntary and involuntary. In his attention restoration theory (ART), voluntary attention filters extraneous stimuli when an individual is attempting to concentrate on a specific task. This voluntary attention undergoes fatigue with time and stress. On the other hand, involuntary attention does not incur fatigue and is stimulated by colors, motion, contrasts 
and the unusual sensory stimuli in garden settings. Consequently, in a natural setting, engaging the involuntary attention may spare voluntary attention fatigue, allowing a more prolonged and higher level of attention. The benefits of improving attention in a garden setting when compared to attention in non-green or traditional rehabilitation settings has been described. ${ }^{51-54}$ Elderly with mild cognitive impairment, dementia, post stroke deficits, or chronic pain may have impaired executive control function (ECF) secondary to cerebral and subcortical changes. Decreased ECF is often accompanied by attention deficits. ${ }^{55-59}$ In such cases, conserving voluntary attention in garden settings during activity or rehabilitation sessions may be advantageous and may shorten outcome times when compared to results achieved in the traditional non-green inpatient rehabilitation settings. ${ }^{7,28}$

Attention deficits may be barriers to cognitive ${ }^{60}$ and functional improvement following brain injury. ${ }^{61}$ The benefit of therapeutic measures to improve alertness and sustained attention for post stroke patients has been reported. ${ }^{62}$ Several studies support the ART hypothesis as a component in attention restoration. Herzog et al. ${ }^{63}$ reported that the perceived restorative effectiveness of natural settings was ranked higher than the perceived restorative effectiveness of sports, entertainment centers and viewing urban settings. Laumann et al. ${ }^{29}$ tested the hypothesis that exposure to nature stimuli improves attention restoration. They reported that reduced autonomic arousal, when viewing a video with nature scenes, resulted in subjects' improved attention and orienting task performance. Using different screen sizes, De Kort et al. ${ }^{54}$ found that attention restoration improved with a corresponding increased sense of immersion (increasing screen dimensions) when viewing nature scenes. Improved performance on attention measures was also reported for students looking out a window at natural scenes when compared to students looking out a window at man-made landscapes. ${ }^{64}$

In a study of more active outdoor participation, Hartig et al..$^{51}$ found a positive correlation between outdoor walking and attention improvement. After 40 minutes of completing a task requiring focused attention, subjects that walked in a wilderness park reported improved mood and decreased errors in proof reading compared to subjects that followed the tasks with a walk in an urban setting or sat in a windowless room listening to music or reading magazines. In another study of attention restoration with pregnant women in their third trimester, Stark ${ }^{52}$ demonstrated that spending two hours a week in nature activities improved concentration and reduced errors. Using a similar protocol, Cimprich et al. ${ }^{53}$ found that two hours of exposure to a natural environment per week improved women's capacity to direct their attention 19 days after breast cancer surgery when compared to controls.

\section{The brain's physiological response to stress}

The brain is the central organ in determining the best response to a level of danger, thus initiating appropriate responses. Physiological and behavioral reactions to stress involve bi-directional communication of the brain with multiple systems, including the endocrine, cardiovascular and immune systems ${ }^{65} \mathrm{~A}$ healthy response to acute stress that promotes adaptation is termed allostatic stress. In contrast, a reaction that promotes a state of chronic stress with negative structural remodeling of the hippocampus, amygdala and prefrontal cortex is termed allosteric load. ${ }^{66}$

The fight or flight model of stress described by Hans Selye ${ }^{67}$ begins by activation of the hypothalamic-pituitary axis (HPA) and the sympathetic systems in addition to the limbic-frontal neurocircuitry system of fear. ${ }^{68}$ Such a response is needed to survive and manage threats such as a house fire or assault. Damage to the brain and body occurs when the stress is chronic, resulting in dysregulation of neurobiologic stress mediators. Allostatic load occurs when the mediators of stress are not turned off after the threat has ceased or when they are not turned on in a manner to adequately manage an immediate threat. ${ }^{66}$

\section{Damage to corticosterone receptors}

For the elderly, the role of chronic stress on the aging brain is particularly important. Loss of hippocampal cells with aging is normative in most cases; however the glucocorticoid hypersecretion syndrome is not. It is suspected that the cytological degeneration of amyloid in the hippocampus and neocortex, including neurofibrillary tangles and neurotic plaques, ${ }^{69}$ in addition to organ aging, combine to accelerate glucocorticoid hypersecretion. ${ }^{70}$ Thus hippocampal damage from a combination of aging, $\mathrm{AD}$ and other trauma appears to promote glucocorticoid hypersecretion as illustrated by elevated basal cortisol and dexamethasone (DEX) resistance. ${ }^{70-73}$

Elevated cortisol levels appear to play an important role in memory ${ }^{74}$ and affective disorders. ${ }^{66}$ Imaging studies with PET and fMRI of persons with recurrent depression altered patterns of activity and decreased volume of the hippocampus, amygdala and prefrontal regions. ${ }^{75-77}$ In major depression, the duration of the symptoms is a stronger predictor of hippocampal volume loss on MRI than is age. ${ }^{76,78}$ Based on these and other findings, it appears that prolonged stress with concurrent neurobiologic changes during aging may accelerate the loss of function and cognition with the end result of an earlier need of health care support due to a declining ability to live independently. ${ }^{57,58,79-81}$

\section{Reduction in stress}

The neurobiology and physiology of the stress response 
provide background for the Overload and Arousal Theory of Ulrich and Parsons. ${ }^{14}$ They proposed that modern society bombards the human central nervous system (CNS) with excessive noise, movement and complex visual stimuli. These stressors eventually overload long-term neural and endocrine dysfunction leading to functional and cognitive decline. It is thought that an environment with the appropriate ratio between plant abundance and hardscape (man made structures) may reduce the deleterious effects of man-made settings to the human inhabitants. The ratio of nature and hardscape to foster a positive therapeutic result has been debated. ${ }^{82}$ Current opinion is that this ratio needs to be greater than $70 \%$ lush garden and less than $30 \%$ hardscape to have a clinical advantage. ${ }^{83}$ Such an environment that includes pleasant smells, colors and shapes of the plants, in addition to less complex visual stimuli, may reduce CNS arousal and reduce short and long term stress. Appropriately designed garden settings may be ideal for experiencing stress modulation ${ }^{30,32}$ and thus have an important therapeutic role for the elderly experiencing the stresses of aging with comorbid medical and psychiatric problems.

Garden settings, both viewed and experienced actively, have already been associated with stress reduction in other populations. Parsons et al. ${ }^{85}$ reported that after a mildly stressful event, subjects viewing simulated drives through nature dominated environs had greater stress reduction, as measured by blood pressure and electrodermal activity, than subjects viewing simulated automobile drives through environs replete with man made hardscape. In another study, subjects viewing pleasant rural scenes on the wall while using a treadmill experienced greater blood pressure reduction than subjects viewing unpleasant urban scenes..$^{26,85}$ Ulrich et al. ${ }^{86}$ found that persons waiting to donate blood had more reduced stress as measured by blood pressure and pulse rate when viewing nature scenes on TV than did donors viewing urban scenes on TV, regular TV programming or no TV programs. Viewing nature scenes not only lowers sympathetic arousal, it may alter EEG activity. Nakamura and Fujii ${ }^{87}$ reported that viewing pictures of a natural hedge produced a greater ratio of alpha to beta activity on EEG when compared to subjects viewing a picture of a similarly shaped concrete wall.

In more active garden activities, Hartig et al. ${ }^{31}$ found that after undergoing tasks to increase psychophysiological stress, a walk in a garden setting improved performance on a test of attention when compared to group members who walked in an urban setting. Restoration of blood pressure, emotion and attention were all more positively affected for the nature group compared to the urban group. A recent study by Van Den Berg and Custers ${ }^{17}$ also involved active participation within gardens. Gardeners whose stress levels had first been deliberately elevated with a difficult task demonstrated significantly lowered salivary cortisol levels and higher self-reported positive mood after 30 minutes of light gardening activities as compared to those who engaged in indoor pleasant reading after the stressful event. Although the relaxing reading did also reduce cortisol levels, this reduction was less than with the gardening, and positive mood showed no increase with the indoor activity. The authors suggest that gardening, as an involved and goal-directed way of interacting with nature, can be valuable in promoting restoration from stress.

Thus, there are numerous studies demonstrating the effect of nature in decreasing sympathetic response and stress. Multiple modalities have been used to measure stress responses, including blood pressure, pulse rate, electrodermal activity, EEG activity, salivary cortisol level and self-reported positive and negative moods. These studies demonstrate the need for more research to determine if there will be a quantitative difference in stress reduction as measured by sympathetic and endocrine responses when the elderly engage in active and passive garden activities compared to similar activities performed in non-garden environments.

\section{BENEFITS FOR RESIDENTS WITH DEMENTIA}

The prevalence of dementia is estimated to be from three to $11 \%$ in community dwellings of elderly older than 65 years of age and up to $47 \%$ in long-term care residents. ${ }^{88,89}$ In one study, $67 \%$ of patients admitted to a long-term care facility were diagnosed as having a dementia syndrome. ${ }^{90}$ Age appropriate environmental strategies have been explored in the attempt to reduce inappropriate behaviors in the elderly with cognitive impairment. Studies with a broad spectrum of ages suggest that having a daily view of a natural setting, or having access to gardens may promote healing and reduce tension. ${ }^{14,91}$ Kuo and Sullivan ${ }^{92}$ reported that knowing there is a park or garden nearby or seeing and having activities in a natural setting may reduce family aggression.

One of the important concepts to be considered in the design of residences for the elderly is to not replicate the modern medical center appearance. The sterile modern medical complex, often without the sight of or access to gardens or natural settings, may increase resident anxiety and fear as evidenced by elevated vital signs. ${ }^{93}$ Anxiety and fear may contribute to inappropriate behaviors, particularly for residents on long term care units. ${ }^{94}$ Dementia unit residents may resent being confined to a locked environment and may express this frustration through aggressive behavior. ${ }^{95,96}$ Cohen-Mansfield et al. ${ }^{97}$ reported that $93 \%$ of nursing home residents had agitated behavior once or more times per week during one shift, 
with a mean of 9.3 weekly reports of inappropriate behaviors. The National Nursing Homes Survey reported that $30-50 \%$ of late stage dementia patients exhibit inappropriate behavior. ${ }^{98}$ It has been suggested that inappropriate behaviors reflect the failure of the environment to meet the needs of the residents. ${ }^{99}$ As dementia patients have a limited capacity to communicate their needs and thoughts, inappropriate behaviors may be interpreted as an index of anxiety and depression. ${ }^{100}$

Entering a rehabilitation center, assisted living or dementia residence requires adjustments that are usually not welcomed by the elderly. Most cognitively impaired elderly making this transition have little possibility of returning to a more independent environment. ${ }^{101}$ The more advanced demented elderly are often dependent on the dementia residence staff for some or most of their activities of daily living (ADLs), and they require being confined to a safe custodial environment with limited exposure to natural settings. ${ }^{96}$ McMinn and Hinton $^{96}$ reported that the mandatory indoor confinement of dementia residents can result in increased verbal and physical agitation and increased use of psychotropic medications. One design intervention to decrease inappropriate behaviors is to increase opportunities for residents to leave the dementia unit to enjoy a garden setting.

Several authors have explored the value of a therapeutic garden for dementia residences. In the residential setting, Namazi and Johnson ${ }^{95}$ reported that having access to unlocked doors leading into a garden might increase autonomy and quality of life. The autonomy of choosing to exit from the residence may reduce the frequency of agitated behavior. Mather, Nemecek, and Oliver ${ }^{102}$ reported that a therapeutic garden reduced the incidence of inappropriate behaviors in a long-term dementia care facility in Canada. McMinn and Hinton ${ }^{96}$ reported decreased inappropriate behaviors following 32 days of confinement of dementia patients when access to an outdoor area was granted. Ellis ${ }^{44}$ found that light exercise in a dementia therapeutic garden could reduce disruptive behaviors. In addition, access to sunlight in the garden can naturally increase production of Vitamin D and help balance a resident's circadian rhythms. ${ }^{103}$

\section{Wander garden studies concerning agitation}

Wander gardens are therapeutic gardens designed specifically for the safety and benefit of residents with dementia. For example, all plants are edible, the garden is enclosed to prevent residents from eloping and all paths lead the residents back to entrances. The number of factors critical to understanding the role of wander gardens for dementia patients is myriad. ${ }^{6}$ Namazi and Johnson ${ }^{95}$ stated that decreased inappropriate behaviors expressed within 30 minutes of finding an unlocked door suggested that a sense of freedom may im- prove the residents' quality of life. Having the option of leaving the indoor residential area for a well designed garden may be useful in reducing agitation and negative behaviors towards other residents and staff. Thus, the question arises: Is there a positive interaction between dementia patients' ambulatory capacities and benefits from the wander garden?

Several studies have suggested that being able to see trees and flowers reduces agitation and aggression and promotes healing. ${ }^{796,102}$ In a prospective observational study, Detweiler et al. ${ }^{48}$ investigated the effect on dementia resident behaviors by adding a wander garden to an existing dementia facility. In this study, 34 male residents were observed for 12 months before and after opening the wander garden. Behaviors were assessed using the Cohen-Mansfield Agitation Inventory Short Form (CMAI), ${ }^{104}$ incident reports, as needed medications (PRNs), and surveys of staff and residents' family members. Results showed that the final CMAI scores and number of PRN medications used were lower than baseline values with a trend for residents who used the garden more often to have less agitated behavior. Staff and family members felt that the wander garden decreased inappropriate behaviors, and improved mood and quality of life of the dementia residents.

Retaining a habit of exercise to assist in supporting ambulatory capacity is an important element in preventive health during aging. ${ }^{105}$ The consequences of visiting a wander garden on monthly agitation levels of a group of elderly veterans diagnosed with dementia was assessed utilizing a growth model within the framework of hierarchical linear modeling. ${ }^{106}$ The focus was on differences in the ambulatory capacity of the veterans using wheelchairs, merry walkers and those ambulating freely. A sample of 34 veterans residing in a locked ward in a dementia unit was observed for a baseline period and for twelve months after a wander garden was opened in their facility. The findings suggest that while visiting the wander garden helped lower agitation levels in all the dementia patients there was a differential effect based on the patients' ability to walk unassisted versus those in wheelchairs and merry walkers, with freely ambulatory patients benefiting more. ${ }^{106}$

\section{Reduction in falls and antipsychotic medications}

In the expanding elderly population, over one third of the community dwellers older than 65 years of age will fall, with $50 \%$ of these elderly experiencing recurrent falls. ${ }^{107-109}$ For the elderly in long-term care facilities, falls and fall-related injuries have been reported to be three times higher than for community-dwelling older adults with a mean of 1.5 falls per institutional bed year. ${ }^{110,111}$ Dementia is an independent risk factor for falls with an increasing incidence as the disease progresses. The yearly estimates of fall prevalence range from $30 \%$ in early dementia to $75 \%$ for institutionalized residents 
with advanced dementia. ${ }^{12}$

Each year the medical costs climb despite the state of the economy. ${ }^{113}$ The total direct cost of all fall injuries for people 65 and older is expected to increase from greater than $\$ 19$ billion in 2000 to about \$55 in 2020 in the USA. ${ }^{114,115}$ Excluding physician fees, the average cost for a fall injury in persons aged 72 and older, was approximately $\$ 19,440 .{ }^{116}$ While about $90 \%$ of falls do not require medical attention, approximately $10 \%$ necessitate medical attention. Moreover, about $5 \%$ of the falls needing medical treatment result in fracture. ${ }^{117,118}$ It is noteworthy that $95 \%$ of hip fractures in the elderly are caused by falls. The mortality for hip fractures in nursing home residents is higher than for community residents with hip fractures. ${ }^{119,120}$

A variety of medications can be employed to treat behavioral disturbances in the elderly with and without dementia. In the residents with dementia, fall risk is often compounded by the side effects of the routine medications employed to treat the comorbid medical problems in addition to those medications prescribed for concurrent depression, agitation, psychosis, anxiety and insomnia. ${ }^{121}$ The most common classes of medications to treat agitation and behavioral problems in dementia include antipsychotics, antidepressants, anxiolytics and hypnotics. ${ }^{122}$ Most of these medications contribute to increased fall risk in the elderly. ${ }^{121}$ Of all medications, psychotropic medications have the highest risk of increasing falls. ${ }^{123-125}$

There is sparse data regarding the influence of a garden on scheduled medication use and fall risk for dementia unit residents. Risk factors for falls are extensive for the moderate to severe dementia residents, with psychiatric medications one of the most prominent. Detweiler et al. ${ }^{126}$ examined the complex interaction of falls and scheduled medications in a garden. The questions investigated were whether a garden had a positive effect on fall frequency and severity and whether it reduced the number and doses of scheduled psychiatric medications used to treat dementia unit residents. The 28 residents experienced about a $30 \%$ decrease for both the raw number of falls and fall severity scores after the garden opened. The raw number of falls decreased $38.7 \%$ for the high garden users compared to $7.9 \%$ for the infrequent garden users. There was a significantly decreased need for high dose antipsychotics, whereas there was relatively no change in primary antidepressant, hypnotic and anxiolytic use. ${ }^{126}$

\section{POSSIBLE LIMITATIONS OF GARDEN SETTINGS}

The patient population most likely to experience negative experiences in garden settings consists of the more advanced dementia patients. It has been reported that advanced demen- tia residents who can see the natural setting but find the doors to the garden locked may experience increased agitation. ${ }^{95}$ On the other hand, a survey of 65 staff members from 10 nursing homes with indoor and outdoor plant activities reported a positive psychological and social effect on the participating dementia residents. Of note, the dementia unit staff reported that the residents ingested both soil and plants with a preference for the more colorful plants and berries. ${ }^{127}$ The dementia wander garden, a subspecialty of garden settings, requires all garden components to be edible, thus excluding toxic plants and pesticides. Consequently, residents eating any garden setting component should not have any serious side effects. It was reported that some staff members responsible for managing the plants may consider resident actions of picking flowers or moving or watering the plants outside of supervised activities as negative resident actions. ${ }^{127}$ During the days when there is rain or snow and the garden doors are open, residents may get wet, requiring a change of clothes. Also, there is a higher probability of having wheelchairs and merry walkers slide off the paths to become stuck in the adjacent mulch or grass after inclement weather. ${ }^{45}$ This may result in more work for the nursing staff and be considered a barrier to garden use.

Finding new and improved answers to elderly health issues has increased the focus on the ethical issues involved in the protection of elderly research subjects. This is particularly relevant for the cognitively impaired, the mentally disabled and the critically ill. Investigators should be aware of the special problems associated with research in the older population and be prepared to deal with these before embarking on a research project. ${ }^{128}$ Informed consent and proxy consent are important issues affecting the design, approval and implementation of research on this diverse, vulnerable population of the institutionalized elderly. As the majority of critically ill adults lack decision-making capacity involving participation in research studies, how do Institutional Review Boards (IRBs) define and weigh risks and benefits in considering research involving capacity and proxy consent. ${ }^{129}$ Gong et al. ${ }^{130}$ examined how IRBs oversee research protocol safeguards for incapacitated adults. They found that IRB practices on surrogate consent and other safeguards to protect incapacitated adults in research varied, from studies including only those patients as having decisional capacity to studies where no assessment of decisional ability was even involved. ${ }^{131}$ If proxies are necessary for consent in a research protocol, to what degree do the proxies' research decisions reflect what patients themselves would decide. ${ }^{129}$ As geriatric research on therapeutic gardens moves forward, progress depends on addressing the many variables in constructing, approving and conducting relevant and ethical studies. 


\section{CONCLUSIONS}

Preliminary studies have reported the benefits of horticultural therapy and garden settings in reduction of pain, improvement in attention, lessening of stress, modulation of agitation, lowering of PRN medications and antipsychotics and reduction of falls. These benefits are important factors in improving the quality of life and possibly reducing costs for long-term, assisted living and dementia unit residents. Most of the existing studies of garden settings have utilized views of nature or indoor plants with sparse studies employing therapeutic gardens and rehabilitation greenhouses. Despite the long history of horticultural therapy in various clinical settings, to the best of our knowledge there are no controlled clinical trials demonstrating the positive or negative effects of the passive or active rehabilitation of the elderly in garden settings. The quantitative analysis of the benefits of garden settings for older individuals is long overdue. Initiating studies regarding the use of therapeutic gardens and/or therapeutic greenhouses may increase the evidence to sustain or refute the benefits of garden settings for persons with similar late life and rehabilitation needs. It would seem that there is a pressing need for scholarly innovative studies investigating this treatment modality for our aging population.

\section{REFERENCES}

1. United Nations, Department of Economic and Social Affairs, Population Division. World Population Prospects: 2010 Revision [CD-ROM]. NY: United Nations; 2011.

2. Greiner PA, Snowdon DA, Schmitt FA. The loss of independence in activities of daily living: the role of low normal cognitive function in elderly nuns. Am J Public Health 1996;86:62-66.

3. McGee SB, Orengo CA, Kunik ME, Molinari VA, Workman RH. Delirium in the geropsychiatric patients: patient characteristics and treatment outcomes. J Geriatr Psychiatry Neurol 1997;10:7-10.

4. Lieberman MA. Symposium--long-time care: research, policy, and practice. Relocation research and social policy. Gerontologist 1974;14: 494-500.

5. Marlowe RA. Effects of environment on elderly state hospital relocates. Paper presented at the 44th Annual Meeting of the Pacific Sociological Association, Scottsdale Arizona; 1973.

6. Detweiler MB, Trinkle DB, Anderson MC. Wander gardens: expanding the dementia treatment environment. Ann Long Term Care 2002; 10:68-74.

7. Detweiler MB, Warf C. Dementia wander garden aids post cerebrovascular stroke restorative therapy: a case study. Altern Thers Health Med 2005;11:54-58.

8. Epstein M, Hansen V, Hazen T. Therapeutic gardens: plant centered activities meet sensory, physical and psychosocial needs. Oreg J Aging 1991;9:8-14.

9. Fisher Center for Alzheimer's Research Foundation, therapeutic activities. Available at: http://www.alzinfo.org/08/treatment-care/therapeutic-activities. Accessed December 12, 2010.

10. Van Den Berg AE. Health Impacts of Healing Environments: A Review of Evidence for Benefits of Nature, Daylight, Fresh Air, and Quiet in Healthcare Settings. Groningen: Foundation 200 Years University Hospital Groningen, Van Eck \& Oosterink, Dodewaard; 2005.
11. Davis S. Development of the Profession of Horticulture Therapy. In: Simpson SP, Strauss MC, Editors. Horticulture as Therapy, Principles and Practice. Binghamton: Haworth Press Inc, 1997, p.3-9.

12. Rush B. Medical inquiries and observations upon diseases of the mind. Philadelphia: Kimber \& Richardson; 1812:226. Available at: http://deila.dickinson.edu/theirownwords/title/0034.htm. Accessed August 28, 2010.

13. Lewis CA. The evolution of horticulture therapy in the US. Paper presented at the Fourth Annual Meeting of the National Council for Therapy and Rehabilitation through Horticulture. Philadelphia, September 6, 1976.

14. Ulrich RS, Parsons R. Influences of Passive Experiences with Plants on Individual Well-Being and Health. In: Diane Relf, Editor. The Role of Horticulture in Human Well-Being and Social Development. Portland: Timber Press, 1992, p.93-105.

15. Whitehouse S, Varni JW, Seid M, Cooper-Marcus C, Ensberg MJ, Jacobs JR, et al. Evaluating a children's hospital garden environment: utilization and consumer satisfaction. J Environ Psychol 2001;21:301-314.

16. Rodiek S. Influence of an outdoor garden on mood and stress in older persons. J Ther Hortic 2002;13:13-21.

17. Van Den Berg AE, Clusters MH. Gardening promotes neuroendocrine and affective restoration from stress. J Health Psychol 2011;16:3-11.

18. Moore B. Growing with Gardening: A Twelve-Month Guide for Therapy, Recreation, and Education. Chapel Hill: University of North Carolina Press; 1989.

19. Relf PD. The Role of Horticulture in Human Well-being and Social Development. Portland: Timber Press; 1992.

20. Hill C, Relf PD. Gardening as an outdoor activity in geriatric institutions. Act Adapt Aging 1982;3:47-54.

21. Matsuo E. Horticulture helps us to live as human beings: providing balance and harmony in our behavior and thought and life worth living. Acta Hortic 1995;391:19-30.

22. Blair D, Giesecke C, Sherman S. A dietary, social, and economic evaluation of the Philadelphia urban gardening project. J Nutr Educ 1991; 23:161-167.

23. Smith DV, Aldous DE. Effect of Therapeutic Horticulture on the SelfConcept of the Mildly Intellectually Disabled Student. In: Francis M, Lindsay P, Stone RJ, Editors. The Healing Dimension of People-Plant Relations: Proceedings of a Research Symposium. CA: University of California Press, 1994, p.215-221.

24. Feenstra G, McGrew S, Campbell D. Entrepreneurial Community Gardens: Growing Food, Skills, Jobs and Communities, Publication 21587. Davis, CA: University of California Press; 1991.

25. Pothukuchi K, Bickes J. Youth Nutrition Gardens in Detroit: A Report on Benefits, Potential, and Challenges. Detroit: Wayne State University; 2001.

26. Pretty J, Hine R, Peacock J. Green exercise: The benefits of activities in green places. J Biol Educ 2006;53:143-148.

27. Lee Y, Kim S. Effects of indoor gardening on sleep, agitation, and cognition in dementia patients--a pilot study. Int J Geriatr Psychiatry 2008; 23:485-489.

28. Irvin KN, Warber SL. Greening healthcare: practicing as if the natural element really mattered. Altern Ther Health Med 2002;8:76-83.

29. Laumann K, Garling T, Stormark KM. Selective attention and heart rate responses to natural and urban environments. J Environ Psychol 2003;23:125-134.

30. Kalevi M, Hartig T, Kaiser FG, Fuhrer U. Restorative experience and self-regulation in favorite places. Environ Behav 2001;33:572-589.

31. Hartig T, Evans GW, Jamner LD, Davis DS, Garling T. Tracking restoration in natural and urban field settings. J Environ Psychol 2003;23: 109-123.

32. Gulwadi GB. Seeking restorative experiences. Environ Behav 2006;38: 503-520.

33. Wichrowski M, Whiteson J, Haas F, Mola A, Rey MJ. Effects of horticultural therapy on mood and heart rate in patients participating in 
an inpatient cardiopulmonary rehabilitation program. J Cardiopulm Rehabil 2005;25:270-274.

34. Hazen T. Case studies part 2; physical disability. Paula: Diagnosis quad amputee. J Hortic 1998;9:32-34.

35. Atherton R, Robertson N. Psychological adjustment to lower limb amputation amongst prosthesis users. Disabil Rehabil 2006;28:12011209.

36. Wichrowski M, Chambers NK, Ciccantelli LM. Stroke, Spinal Cord and Physical Disabilities in Horticulture Therapy Practices. In: Simson SP, Straus MC, Editors. Horticulture as Therapy Principals and Practice. New York: Food Products Press, an Imprint of Hawthorn Press, 1998, p.71-104.

37. Fleming K, Alford DO. Case studies part 2; physical disability. Vanessa: Diagnosis demyelinating encephalitis with hemiplegia. J Hortic 1998;9:35-36.

38. Karph A. Case studies part 2; physical disability. Caroline: Diagnosis depressive disorder NOS. J Hortic 1998;9:42.

39. Szofran J. Case studies part 2; physical disability. Ethel: Diagnosis chronic degenerative arthritis, bilateral total knee replacement. J Hortic 1998;9:31-32.

40. Relf PD. People-Plant Relationship. In: Simson SP, Straus MC, Editors. Horticulture as Therapy Principals and Practice. New York: Food Products Press, an Imprint of Hawthorn Press, 1998, p.23-42.

41. Orians GH, Heerwagen JH. Evolved Responses to Landscapes. In: Barkow JH, Cosmides L, Tooby J, Editors. The Adapted Mind, Evolutionary Psychology and Generation of Culture. New York: Oxford University Press, 1992, p.555-579.

42. Laben JK. Wandering: a current problem, nursing's responsibility for effective management. J Nurs Law 1997;4:65-71.

43. Weisman GD, Cohen U, Ray K, Day K. Architectural Planning and Design for Dementia Care Units. In: Coons DH, Editor. Specialized Dementia Care Units. Baltimore: The Johns Hopkins University Press, 1991, p.93-98.

44. Ellis DJ. Garden and the Alzheimer's patients. Am Hortic 1995;74:76.

45. Detweiler MB, Murphy PF, Myers LC, Kim KY. Does a wander garden influence inappropriate behaviors in dementia residents? Am J Alzheimers Dis Other Demen 2008;23:31-45.

46. Diette GB, Lechtzin N, Haponik E, Devrotes A, Rubin HR. Distraction therapy with nature sights and sounds reduces pain during flexible bronchoscopy: a complementary approach to routine analgesia. Chest 2003;123:941-948.

47. Ulrich RS. View through a window may influence recovery from surgery. Science 1984;224:420-421.

48. Walch JM, Rabin BS, Day R, Williams JN, Choi K, Kang JD. The effect of sunlight on postoperative analgesic medication use: a prospective study of patients undergoing spinal surgery. Psychosom Med 2005; 67:156-163.

49. Park S. Randomized clinical trials evaluating therapeutic influences of ornameltal indoor plants in hospital rooms on health outcomes of patients recovering from surgery. Kansas State Research Exchange 2006. Available at:http://krex.k-state.edu/dspace. Accessed November 22, 2007.

50. James W. Psychology: The Briefer Course. Notre Dame: University of Notre Dame Press; 1985.

51. Hartig T, Mang M, Evans GW. Restoration effects of natural environment experiences. Environ Behav 1991;23:3-36.

52. Stark MA. Restoring attention in pregnancy: the natural environment. Clin Nurs Res 2003;12:246-265.

53. Cimprich B, Ronis DL. An environmental intervention to restore attention in women newly diagnosed with breast cancer. Cancer Nurs 2003;26:284-292.

54. de Kort YAW, Meijnders AL, Sponselee AAG, IJsselsteijn WA. What's wrong with virtual trees? Restoring from stress in a mediated environment. J Environ Psychol 2006;26:309-320.

55. Royall DR, Mahurin RK, Gray KF. Bedside assessment of executive cognitive impairment: the executive interview. J Am Geriatr Soc 1992; 40:1221-1226.

56. Royall DR, Mahurin RK, True JE, Anderson B, Brock IP 3rd, Freeburger L, et al. Executive impairment among the functionally dependent: Comparisons schizophrenic and elderly subjects. Am J Psychiatry 1993;150:1813-1819.

57. Royall DR, Jeffrey JA, Polk M. CLOX: An executive clock drawing task. J Neurol Neurosurg Psychiatry 1998;64:588-594.

58. Royall DR. Executive cognitive impairment: a novel perspective on dementia. Neuroepidemiology 2000;19:293-299.

59. Royall DR, Lauterbach EC, Cummings JL, Reeve A, Rummans TA, Kaufer DI, et al. Executive control function: a review of its promise and challenges for clinical research. A report from the Committee on Research of the American Neuropsychiatric Association. J Neuropsychiatry Clin Neurosci 2002;14:377-405.

60. Gouvier WD. Assessment and treatment of cognitive deficits in braindamaged individuals. Behav Modif 1987;11:312-328.

61. Pohl PS, Lorie G. Richards LG. Decreasing stroke deficits. April/May 2000. Available at: www.nrhcares.com/programs/stroke.php. Accessed July 17, 2008.

62. Lincoln NB, Majid MJ, Weyman N. Cognitive rehabilitation for attention deficits following stroke. Cochrane Database of Systematic Reviews. 2000, Issue 4. Art. No.: CD002842. DOI: 10.1002/14651858. CD002842.

63. Herzog TR, Black AM, Fountaine KA, Knotts DJ. Reflection and attentional recovery as distinctive benefits of restorative environments. J Environ Psychol 1997;17:165-170.

64. Tennessen CM, Cimprich B. Views to nature: effects on attention. J Environ Psychol 1995;15:77-85.

65. Viamontes GI, Nemeroff CB. Brain-body interactions: the physiological impact of mental processes- the neurobiology of the stress response. Psychiatr Ann 2009;39:975-984.

66. McEwen BS. Physiology and neurobiology of stress and adaptation: central role of the brain. Physiol Rev 2007;87:873-904.

67. Selye $H$. The general adaptation syndrome and diseases of adaptation. J Clin Endocrinol 1946;6:217-230.

68. Amstadter AB, Nugent NR, Koenen KC. Genetics of PTSD: Fear Conditioning as a Model for Future Research. Psychiatr Ann 2009;39: 358-367.

69. Terry RD, Katzman R. Senile dementia of the Alzheimer type. Ann Neurol 1983;14:497-506.

70. Sapolsky RM, Krey LC, McEwen BS. The neuroendocrinology of stress and aging: the glucocorticoid cascade hypothesis. Endocr Rev 1986;7:284-301.

71. Spar JE, Gerner R. Does the dexamethasone suppression test distinguish dementia from depression? Am J Psychiatry 1982;139:238-240.

72. Raskind M, Peskin E, Rivard MF, Veith R, Barnes R. Dexamethasone supression test and cortisol and circadian rhythm in primary degenerative dementia. Am J Psychiatry 1982;139:1468-1471.

73. Carnes M, Smith JC, Kalin NH, Bauwens SF. Effects of chronic medical illness and dementia on the dexamethasone supression test. J Am Geriatr Soc 1983;31:267-271.

74. Wang J, Rao H, Wetmore GS, Furlan PM, Korczykowski M, Dinges $\mathrm{DF}$, et al. Perfusion functional MRI reveals cerebral blood flow pattern under psychological stress. Proc Natl Acad Sci U S A 2005;102:1780417809.

75. Drevets WC, Price JL, Simpson JR Jr, Todd RD, Reich T, Vannier M, et al. Subgenual prefrontal cortex abnormalties in mood disorders. Nature 1997;386:824-827.

76. Sheline YI, Sanghavi M, Mintun MA, Gado MH. Depression duration but not age predicts hippocampal volume loss in medically healthy women with recurrent major depression. J Neurosci 1999;19:50345043.

77. Sheline YI, Gado MH, Kraemer HC. Untreated depression and hippocampal volume loss. Am J Psychiatry 2003;160:1516-1518. 
78. Starkman MN, Gebarski SS, Berent S, Schteingart DE. Hippocampal formation volume, memory dysfunction, cortisol levels in patients with Cushing's syndrome. Biol Psychiatry 1992;32:756-765.

79. Jacobson L, Sapolsky R. The role of the hippocampus in feedback regulation of the hypothalamic-pituitary-adrenocortical axis. Endocr Rev 1991;12:118-134.

80. Herman JP, Cullinan WE. Neurocircuitry of stress: central control of the hypothalamo-pituitary-adrenocortical axis. Trends Neurosci 1997; 20:78-84.

81. Royall DR. Frontal systems impairment in major depression. Semin Clin Neuropsychiatry 1999;4:13-23.

82. Thompson JW. A question of healing. Landsc Archit 1998; 88:68-92.

83. Marcus CC. Personal conversation with S. Lane, Horticulturist. Health Garden Design Certification Program. Chicago: Chicago Botanic Garden; 2008.

84. Parsons R, Tassinary LG, Ulrich RS, Hebl MR, Grossman-Alexander $M$. The view from the road: implications for stress recovery and immunization. J Environ Psychol 1998;18:113-139.

85. Pretty J, Peacock J, Sellens M, Griffin M. The mental and physical health outcomes of green exercise. Int J Environ Health Res 2005;15: 319-337.

86. Ulrich RS, Simons RF, Miles MA. Effects of environmental simulations and television on blood donor stress. J Archit Plann Res 2003;20: 38-47.

87. Nakamura R, Fujii E. A comparative study of the characteristics of the electroencephalogram when observing a hedge and a concrete block fence. J Jpn Inst Landsc Archit 1992;55:139-144.

88. Canadian Study of Health and Aging Working Group. Canadian Study of Health and Aging: study methods of and prevalence of dementia. Can Med Accos J 1996;150:899-913.

89. Evans DA, Funkenstein HH, Albert MS, Scherr PA, Cook NR, Chown MJ, et al. Prevalence of Alzheimer's disease in a community population of older persons. Higher than previously reported. JAMA 1989;262: 2551-2556.

90. Rovner BW, German PS, Broadhead J, Brant LJ, Blaustein J, Folstein MF. The prevalence and management of dementia and other psychiatric disorders in nursing homes. Int Psychogeriatr 1990;2:13-24.

91. Kaplan R, Kaplan S. The Experience of Nature: A Psychological Perspective. New York: The Cambridge University Press; 1996.

92. Kuo FE, Sullivan WC. Environment and crime in the inner city: does vegetation reduce crime? Environ Behav 2001;33:343-367.

93. Malkin J. Hospital Interior Architecture. New York: Van Nostrand, Reinhold; 1992.

94. Tariot PN, Ryan JM, Porsteinsson AP, Loy R, Schneider LS. Pharmacologic therapy for behavioral symptoms of Alzheimer's disease. Clin Geriatr Med 2001;17:359-376.

95. Namazi KH, Johnson BD. Pertinent autonomy for residents with dementias: Modification of the physical environment to enhance independence. Am J Alzheimers Care Relat Disord Res 1992;7:16-21.

96. McMinn BG, Hinton L. Confined to barracks: the effects of indoor confinement on aggressive behavior among inpatients of an acute psychogeriatric unit. Am J Alzheimers Dis Other Demen 2000;15:3641.

97. Cohen-Mansfield J, Marx MS, Rosenthal AS. A description of agitation in a nursing home. J Gerontol 1989;44:M77-M84.

98. U.S. Department of Health and Human Services. National Center for Health Statistics: The national home survey, Series 13, \#97. Hyattsville, MD: DDHS, USPHS, \#89-1758; 1989.

99. Cohen-Mansfield J. Nonpharmacologic interventions for inappropriate behaviors in dementia: a review, summary, and critique. Am J Geriatr Psychiatry 2001;9:361-381.

100. Patel V, Hope RA. A rating scale for aggressive behaviour in the elderly--the RAGE. Psychol Med 1992;22:211-221.

101. Covinsky KE, Palmer RM, Fortinsky RH, Counsell SR, Stewart AL, Kresevic D, et al. Loss of independence in activities of daily living in older adults hospitalized with medical illnesses: increased vulnerability with age. J Am Geriatr Soc 2003;51:451-458.

102. Mather JA, Nemecek D, Oliver K. The effect of a walled garden on behavior of individual's with Alzheimer's. Am J Alzheimer Dis 1997;12: 252-257.

103. Portale AA, Halloran BP, Morris RC Jr. Dietary intake of phosphorus modulates the circadian rhythm in serum concentration of phosphorus. Implications for the renal production of 1,25-dihydroxyvitamin D. J Clin Invest 1987;80:1147-1154.

104. Cohen-Mansfield J. Assessment of agitation. Int Psychogeriatr 1996;8: 233-245.

105. Rowe JW, Kahn RL. Human aging: usual and successful. Science 1987; 237:143-149.

106. Murphy PF. Miyazaki Y, Detweiler MB, Kim KY. Longitudinal analysis of effects of a wander garden for dementia patients based on ambulation ability. Dementia 2010;9:355-373.

107. Tinetti ME, Speechley M, Ginter SF. Risk factors for falls among elderly persons living in the community. N Engl J Med 1988;319:1701-1707.

108. Hausdorff JM, Rios DA, Edelberg HK. Gait variability and fall risk in community-living older adults: a 1-year prospective study. Arch Phys Med Rehabil 2001;82:1050-1056.

109. Nevitt MC, Cummings SR, Kidd S, Black D. Risk factors for recurrent nonsyncopal falls. A prospective study. JAMA 1989;261:2663-2668.

110. Rubenstein LZ, Josephson KR, Robbins AS. Falls and Their Prevention. In: Besdine RW, Rubenstein LZ, Snyder L, Editors. Medical Care of the Nursing Home Resident. Philadelphia: American College of Physicians, 1996, p.103-115.

111. Beers MH, Berkow R. The Merck Manual of Geriatrics, 3rd Edition. Whitehouse Station, NJ: Merck \& Co; 2000.

112. Rabins PV, Lyketsos CG, Steele CD. Noncogntive Functional Disorders and Disturbances in Sleeping, Eating and Sexuality. In: Rabins PV, Lyketsos CG, Steele CD, Editors. Practical Dementia Care. New York: Oxford University Press, 2006, p.169-200.

113. Levey NN. U.S. healthcare costs projected to continue to climb. Tribune Washington Bureau, September 09, 2010. Available at: http://articles.latimes.com/2010/sep/09/nation/la-na-health-costs-20100909 Accessed December 17, 2010.

114. Stevens JA, Corso PS, Finkelstein EA, Miller TR. The costs of fatal and nonfatal falls among older adults. Inj Prev 2006;12:290-5.

115. Englander F, Hodson TJ, Terregrossa RA. Economic dimensions of slip and fall injuries. J Forensic Sci 1996;41:733-746.

116. Rizzo JA, Friedkin R, Williams CS, Nabors J, Acampora D, Tinetti ME. Health care utilization and costs in a Medicare population by fall status. Med Care 1998;36:1174-1188.

117. Rubenstein LZ, Josephson KR, Osterweil D. Falls and fall prevention in the nursing home. Clin Geriatr Med 1996;12:881-902.

118. Morley JE. Falls--where do we stand? Mo Med 2007;104:63-67.

119. Baker SP, Harvey AH. Falls injuries in the elderly. Clin Geriatr Med 1985;1:501-512.

120. Rhymes J, Jaeger R. Falls. Prevention and management in the institutional setting. Clin Geriatr Med 1988;4:613-622.

121. Buckwalter K, Katz I, Martin H. Guide to the Prevention of Falls in the Elderly. New York: McMahon Publishing Group; 2003.

122. Alexopoulos G, Jeste DV, Chung H, Carpenter D, Ross R, Docherty JP. Treatment of Dementia and Its Behavioral Disturbances. The Expert Consensus Guideline Series; A Postgraduate Medicine Special Report (No. 6-22); 2005.

123. Leipzig RM, Cummings RG, Tinetti ME. Drugs and falls in older people: a systemic review and meta-analysis: I. Psychotropic drugs. J Am Geriatr Soc 1999;47:30-39

124. Leipzig RM, Cummings RG, Tinetti ME. Drugs and falls in older people: a systemic review and meta-analysis: II. Cardiac and analgesic drugs. J Am Geriatr Soc 1999;47:40-50.

125. Sleeper R, Bond CA, Rojas-Fernandez C. Psychotropic drugs and falls: new evidence pertaining to serotonin reuptake inhibitors. Pharmaco- 
therapy 2000;20:308-317.

126. Detweiler MB, Murphy PF, Kim KY, Myers LC, Ashai A. Scheduled medications and falls in dementia patients utilizing a wander garden. Am J Alzheimers Dis Other Demen 2009;24:322-332.

127. Rappe E. The Influence of a Green Environment and Horticultural Activities on the Subjective Well-Being of the Elderly Living in LongTerm Care (Academic Dissertation). 2005. University of Helsinki, Department of Applied Biology. Publication 24:1-49.

128. Schechter BM. Ethics in Geriatric Research. J Pharm Pract 1988;1:235242.
129. Dunn LB, Misra S. Research ethics issues in geriatric psychiatry. Psychiatr Clin North Am 2009;32:395-411.

130. Gong MN, Winkel G, Rhodes R, Richardson LD, Silverstein JH. Surrogate consent for research involving adults with impaired decision making: survey of Institutional Review Board practices. Crit Care Med 2010; 38:2146-2154.

131. Kim SY, Appelbaum PS, Jeste DV, Olin JT. Proxy and surrogate consent in geriatric neuropsychiatric research: update and recommendations. Am J Psychiatry 2004;161:797-806. 